\title{
VIVENCIANDO O CONJ UNTO DE CIRCUNSTÂNCIAS QUE INFLUENCIAM NA SIGNIFICAÇÃO DA ALTA HOSPITALAR: ESTUDO DE ENFERMAGEM
}

\author{
Experiencing the set of circumstances that influence the significance of hospital discharge: \\ nursing study \\ Vivencia del conj unto de circunstancias que inciden en la importancia del alta hospitalaria: \\ estudio de enfermería
}

Glaucia Valente Valadares²

\begin{abstract}
RESUMO
A presente discussão é parte integrante da dissertação de mestrado intitulada: "Ressignificando a alta hospitalar e percebendo-se como o cuidador familiar: um estudo de enfermagem", vinculada à Escola de Enfermagem Anna Nery. Teve como objeto o significado da alta hospitalar para a família do cliente com sequelas do acidente vascular cerebral. 0 objetivo traçado para esta discussão foi: discutir o contexto vivido pelo cuidador familiar, considerando o duelo de sentimentos, de manifestações, de atitudes e de práticas. Foram adotados o referencial teórico do Interacionismo e o método Teoria Fundamentada nos Dados. 0 estudo foi realizado em um hospital público municipal. Os atores sociais foram cuidadores familiares de vítimas de um acidente vascular. A partir da análise das categorias, o fenômeno revela o entendimento do conjunto de circunstâncias que acompanham 0 acontecimento e que, ao se articularem, interferem no significado que os familiares concedem à alta hospitalar.
\end{abstract}

Palavras-chave: Cuidados de enfermagem. Enfermagem familiar. Acidente vascular cerebral. Alta do paciente

\begin{abstract}
This discussion is part of the dissertation entitled: "Resignifying discharge and perceive themselves as family caregivers: a study of nursing", linked to Anna Nery School of Nursing. It had as its object the meaning of the hospital for the client's family with sequelae form a stroke. The objective set for this discussion was: discuss the context experienced by family caregivers considering the dueling feelings, expressions, attitudes and practices. The theoretical approach was Interactionism, which was adopted the method Grounded Theory. The study was conducted at a public hall. The participants were family caregivers of victims of a stroke. From the analysis of the phenomenon categories reveals an understanding of the set of circumstances surrounding the event and to articulate meaning that interfere with family grant discharge.
\end{abstract}

Keywords: Nursing Care. Family Nursing. Stroke. Patient Discharge

\section{Resumen}

Este debate forma parte de la tesis titulada: "Nuevo significado del alta hospitalaria y percepción de si propio como el cuidador familiar: un estudio de enfermería", vinculado a la Escuela de Enfermería Anna Nery. Tenía por objeto el significado del hospital para la familia del cliente con secuelas de ictus. El objetivo fijado para esta discusión fue: analizar el contexto vivido por los cuidadores de la familia teniendo en cuenta los sentimientos de duelo, expresiones, actitudes y prácticas. El enfoque teórico fue el Interaccionismo. Fue adoptado el método Grounded Theory. El estudio se realizó en una sala pública. Los participantes eran cuidadores familiares de las víctimas de un accidente cerebrovascular. A partir del análisis de las categorías, el fenómeno revela una comprensión del conjunto de circunstancias que rodean el caso y que, para articularse, interfieren con el significado de que miembros de la familia conceden a alta hospitalaria.

Palabras clave: Atención de Enfermería. Enfermería de la Familia. Accidente Cerebrovascular. Alta del Paciente

\footnotetext{
${ }^{1}$ Mestre em Enfermagem. Membro do Grupo de Pesquisa Teoria Fundamentada nos Dados: estudos de enfermagem. Professora Substituta da Universidade Federal do Rio de Janeiro - Campus Macaé. Rio de Janeiro-RJ. Brasil. Email: paiva.raquels@gmail.com; ${ }^{2}$ Doutora em Enfermagem. Membro do Núcleo de Pesquisa de Fundamentos do Cuidado de Enfermagem (Nuclearte). Membro do Grupo de Pesquisa Teoria Fundamentada nos Dados: estudos de enfermagem. Professora Adjunta da Universidade Federal do Rio de janeiro. Coordenadora do Curso de Enfermagem - Campus Macaé. Cabo Frio-RJ. Brasil. Email: glauciavaladares@ig.com.br
} 


\section{INTRODUÇÃO}

A presente discussão é parte integrante da dissertação de mestrado intitulada: "Ressignificando a alta hospitalar e percebendo-se como o cuidador familiar: um estudo de enfermagem", vinculada ao Núcleo de Fundamentos do Cuidado de Enfermagem (NUCLEARTE) da Escola de Enfermagem Anna Nery da Universidade Federal do Rio de Janeiro (EEAN-UFRJ), defendida e aprovada em dezembro de 2011. A referida dissertação teve como objeto de estudo o significado da alta hospitalar para a família do cliente com sequelas do acidente vascular cerebral.

Neste início de século XXI, as doenças cardiovasculares representam 32,2\% das mortes no Brasil, sendo o acidente vascular cerebral (AVC) a principal causa dentre todas as doenças do aparelho cardiovascular' ${ }^{1}$. Cabe destacar que o AVC acomete, com maior frequência, indivíduos com mais de 65 anos de idade, e, considerando o rápido e intenso envelhecimento da população brasileira, estima-se que este evento seja cada vez mais impactante para a saúde pública brasileira.

0 indivíduo acometido por um AVC precisa reformular seus hábitos e estilo de vida, que pode afetar a família, primeiro grupo de relações em que está inserido. Surgem dúvidas quanto às causas e as consequências, duração das sequelas, possibilidade de recuperação e, principalmente, como se comportar e agir diante da nova realidade. Neste sentido, devese considerar que a família sofrerá significativo impacto diante do referido evento.

0 AVC pode ser considerado um evento novo e inesperado na vida tanto do cliente quanto daqueles que formam sua rede social. Do mesmo modo, é importante que a família, além do ente adoecido, esteja amparada nesses momentos de crise, dúvidas e incertezas. Portanto, tem-se como imprescindivel pensar nas necessidades e desejos destes sujeitos, objetivando prepará-los para o cuidado no domicílio.

As doenças crônico-degenerativas, como o AVC, evidenciam o papel da família como centro da prestação de cuidados. Diante do adoecimento de um membro, todos os outros são atingidos. Cabe pensar que é no contexto familiar que a doença evolui, surgem os problemas e as possíveis soluções. Os familiares vivenciam e se envolvem em todas as fases do adoecer, oferecendo suporte no cuidado ao cliente.

Sobre família, cabe destacar que: o conceito em voga transcende 0 aspecto biológico de consanguinidade, tornandose mais amplo. As famílias vivem diversas composições. De tal modo, o que realmente une uma pessoa a outra são os laços de parentescos e/ou afinidades. Deste modo, pode-se conceber a família como uma associação de pessoas que convive por razões afetivas, assumindo o compromisso de cuidado mútuo.

É no espaço da família que ocorrem as primeiras experiências de relacionamento e de aprendizagem, transmitindo valores que orientam o indivíduo na construção e na organização da sua vida. A família pode ser vista como uma instância da sociedade em que passado, presente e futuro se encontram. A família é a base fundamental para a vida humana, responsável pelo acolhimento, proteção e cuidado, com funções: biológica, educacional, psicológica, social, emocional e histórica?

No que se refere ao cuidado de um familiar com sequelas do AVC após a alta hospitalar, é preciso pensar que uma doença crônica tende a modificar completamente o cotidiano das famílias. As mudanças ambientais, na infraestrutura e nas relações sociais são inevitáveis, objetivando manter a segurança e o bem-estar do ente enfermo ${ }^{3}$.

Assim, os profissionais de saúde devem considerar e avaliar as implicações da doença para os familiares do cliente hospitalizado ou em tratamento ambulatorial. Para que 0 cuidado possa ser confiado aos familiares, estes precisam ser apoiados e incentivados pelos profissionais de saúde.

0 cuidado no domicílio é necessário e essencial ao tratamento das vítimas do AVC ${ }^{4}$. Diante disso, a família necessita ser bem preparada para cuidar, caso contrário, pode apresentar dificuldades em assistir o ente adoecido, considerando que a limitação da atividade física e a intelectual acometem grande parte dos sobreviventes do infortuito. Logo, a situação da perda de independência e, até mesmo, perda da autonomia geram a necessidade de um auxiliar para o indivíduo quando este retorna ao domicílio.

0 estudo mostra-se relevante por considerar que a família do cliente com sequelas do AVC, possível prestadora do cuidado no domicilio, deve ser alvo da assistência de enfermagem uma vez que o impacto provocado pela doença pode gerar dificuldades em cuidar do ente adoecido. Por meio de uma relação de confiança e de parceria o enfermeiro auxiliará 0 familiar a enfrentar a novidade de cuidar.

Além disso, pensando e refletindo sobre o significado atribuído pela família à alta hospitalar, é possível depreender aspectos que, somados, podem propiciar teorizações, que relacionem: o cliente, o ambiente, a família, as tecnologias em saúde e as possíveis estratégias adotadas, entre muitos outros aspectos. Ainda, em que pese à essência mesma do objeto, os cuidados fundamentais estarão presentes, já que são muitas as demandas exigidas quando do evento AVC; por conseguinte, eles serão trabalhados, especialmente os relacionados à expressividade para e com o outro (cliente e família).

Cuidar de um familiar adoecido configura-se em uma grande responsabilidade e desafio. Novos recursos de enfrentamento precisam ser adotados pela família que se encontra afetada e desestruturada. A partir do significado que atribui ao evento de adoecimento, a família busca um equilibrio, objetivando se adaptar à nova realidade e auxiliar na recuperação do familiar acometido por uma doença.

Neste sentido, o presente recorte destaca 0 entendimento do conjunto de circunstâncias que acompanham o acontecimento e que, ao se articularem, interferem no significado que os propensos cuidadores familiares concedem a 
alta hospitalar. Assim, nos deteremos a discutir o contexto, que apresenta as especificidades pertencentes ao fenômeno, que identificam a sua dimensão.

Portanto, o objetivo traçado foi discutir o contexto vivido pelo cuidador familiar, considerando o duelo de sentimentos, de manifestações, de atitudes e de práticas.

\section{REFERENCIAL TEÓRICO}

Com a finalidade de compreender o significado que o cuidador familiar concede à alta hospitalar, adotou-se como referencial teórico o Interacionismo Simbólico (IS), que se apoia em três premissas, a saber: o ser humano age em relação às coisas com base nos significados que elas têm para ele; 0 significado destas coisas é derivado, ou se origina da interação social que o indivíduo estabelece com outras pessoas; e estes significados são manipulados e modificados através de um processo interpretativo usado pelo sujeito ao tratar as coisas e situações que o mesmo encontra 5 .

Na perspectiva do Interacionismo Simbólico, o significado emerge do processo de interação entre os indivíduos, em vez da percepção como algo intrínseco ao ser, seja como uma expressão dos elementos constituintes da psique, da mente ou da organização psicológica ${ }^{5}$.

\section{MÉTODO}

0 estudo, de abordagem qualitativa, teve como método a Teoria Fundamentada nos Dados (TFD) ou Grounded Theory, que trata de entender com profundidade, por meio de uma análise sistemática, os processos nos quais estão acontecendo os fenômenos.

0 propósito da TFD é a construção de uma teoria com base nos dados investigados, obtidos de maneira indutiva ou dedutiva em um determinado objeto da realidade. Esses dados são, em seguida, firmados em categorias conceituais que podem explicar um fenômeno. Assim, o pesquisador identifica padrões, pontos em comum e relacionamento, por meio da análise de instâncias e eventos ${ }^{6}$.

Considerando que as associações entre categorias podem ser muito sutis e, na intenção de aprofundar a Teoria, adotou-se o modelo paradigmático. Trata-se de um esquema organizacional utilizado para classificar e organizar as conexões teóricas emergentes, apresentando os seguintes componentes básicos: condições causais, contexto, condições intervenientes, estratégias de ação-interação e, por fim, as consequências?.

Foram respeitados os preceitos das Diretrizes e Normas Regulamentadoras de Pesquisas Envolvendo Seres Humanos, do Conselho Nacional de Saúde, tendo em vista a Resolução n 196/96 do Ministério da Saúde, que trata de pesquisas envolvendo seres humanos. Para tal, o presente estudo foi submetido ao Comitê de Ética e Pesquisa (CEP), da Secretaria Municipal de Saúde e Defesa Civil do Rio de Janeiro (Parecer $\left.n^{\circ} 90 A / 2011\right)$.

A produção de dados ocorreu por meio da entrevista semiestruturada em profundidade e da observação participante assistemática. 0 momento da visita hospitalar é uma oportunidade ótima para interação entre cliente, família e equipe de saúde. Entendendo que este é um momento oportuno para observar a relação da equipe de saúde com os familiares, no que se refere ao preparo para alta hospitalar, foi realizada a observação participante assistemática.

As entrevistas individuais em profundidade foram realizadas conforme a disponibilidade dos familiares, em local e horários previstos, bem como agendados no primeiro contato. Deste modo, ocorreram após a visita hospitalar, em local reservado fora da enfermaria, permitindo que os entrevistados expressassem as suas percepções. A observação participante assistemática ocorreu em dois dias, antes e após a entrevista semiestruturada, com a finalidade de complementar os dados obtidos e verificar a necessidade de realizar novas perguntas após a observação.

Considerando os aspectos apresentados, a análise seguiu os passos da Teoria Fundamentada nos Dados. Sendo assim, foi utilizada a amostragem teórica, e a coleta ocorreu até que a saturação (de forma cíclica) fosse atingida, quando se verificaram a repetição e a ausência de dados novos, assim como a crescente compreensão dos conceitos identificados.

Cabe mencionar que o número de familiares entrevistados foi configurado a partir da análise das entrevistas e das observações realizadas. A produção de dados indicou a necessidade de novas coletas, com a finalidade de melhor delinear as categorias. Destaco que, na medida em que as categorias se formaram e, conforme a necessidade, novas perguntas foram feitas.

Para melhor compreensão dos dados e seguindo os preceitos da TFD, foi adotado o diagrama (Figura 1), um mecanismo gráfico desenvolvido com a intenção de visualizar as relações entre os conceitos estabelecidos e as propriedades relacionadas, facilitando o entendimento da realidade investigada.

\section{RESULTADOS}

Participaram do estudo nove familiares (Quadro 1) de clientes hospitalizados vítimas de um primeiro episódio do AVC, apresentando incapacidade moderada ou grave. Para assegurar o anonimato dos participantes, foi utilizada a letra "E" e 0 número correspondente à fala, identificados no estudo como [E1], [E2], e assim por diante.

No processo de análise referente ao contexto do fenômeno, emergiram as seguintes categorias: "Trazendo à memória as características do familiar antes do acidente vascular cerebral"; "Tentando justificar o acometimento pelo acidente vascular cerebral"; "Percebendo as peculiaridades do acidente vascular cerebral" e "Esperando o dia da alta hospitalar". 
"Trazendo à memória as características do familiar antes do acidente vascular cerebral" destaca algumas características do indivíduo adoecido, abordando aspectos de saúde e de doença (processual). A categoria aborda o papel que 0 adoecido representava no âmbito familiar. É importante observar que, no discurso, o entrevistado traz o verbo mudar, que representa exatamente a necessidade de modificar os papéis.

Vamos cuidar dela. Tudo mudou agora. Ela cuidava da gente, agora mudou. [E3]

Outro fator que merece destaque são os discursos referentes à vida que o familiar tinha antes do AVC, mostrando o quanto 0 acometimento pela doença mudará os seus hábitos de vida.

Ele trabalha, tem a vida dele, a vida com a familia. [E4]

A doença, com destaque para a doença crônica, significa a perda de equilíbrio e a necessidade de ajustamento às limitações e às novas condições, ou seja, uma nova relação com a vida precisa ser estabelecida. A família (primeiro grupo social afetado pelo adoecimento de um indivíduo) sofrerá as influências desta nova realidade.

A categoria "Tentando justificar o acometimento pelo acidente vascular cerebral" aborda mais diretamente os depoimentos que versam sobre os hábitos de vida do familiar e os eventos estressores, que podem ter provocado o AVC. Trata-se, portanto, da tentativa de justificar ou buscar uma causa para a enfermidade.

Ninguém consegue fazer ele parar de fumar. Ele já não andava muito bem, por causa da idade mesmo, ficou sedentário, quase não saia de casa, nem pra fazer exercício. [E2]

"Percebendo as peculiaridades do acidente vascular cerebral" configura-se uma categoria de extrema relevância, já que a família assumirá o cuidado após a alta hospitalar. Por conseguinte, é importante que ela conheça as restrições conferidas. Os discursos destacam o familiar associando a sequela à dependência e à necessidade de ajudar.

Então, como ele está com um lado do corpo paralisado, ele depende de alguns cuidados específicos e de ajuda mesmo pra fazer uma ou outra coisa. [E4]

Para muitos cuidadores, apesar da segurança que 0 ambiente hospitalar fornece no que se refere à prestação de cuidados, o retorno do familiar convalescido para o domićlio favorecerá na recuperação. Portanto, os familiares ficam "Esperando o dia da alta hospitalar".

É possivel perceber, pelos discursos, que os familiares associam a alta hospitalar a uma melhoria no estado de saúde do familiar. Para eles, o tempo de permanência no hospital significa que o familiar não está em condiç̃̃es de voltar para o domicílio e receber tratamento ambulatorial.

Quero muito que ele vá logo para casa. A sensação que eu tenho é que a alta significa que ele está melhor. Se ele fica aqui, parece que é porque não está bem ou porque corre riscos e tem que ser observado pela equipe. [E7]

Em contrapartida, apesar da sensação de felicidade, a proximidade da alta hospitalar traz algumas preocupações, que se relacionam às mudanças que ocorrerão na vida da família e ao frequente despreparo para cuidar.

Estou bem ansiosa por esse dia. Mesmo sabendo que o cuidado em casa vai ser bem trabalhoso, eu estou esperando pelo dia da alta. [E7]

0 fenômeno "Percebendo que a teia social modula e modifica a significação da alta hospitalar" elucida 0 complexo mundo das famílias e o seu singular processo de viver. Deve-se considerar que a origem, a cultura, a religião e a orientação filosófica (dentre outros) são fatores relevantes na construção do significado que cada indivíduo concede à teia social a qual está inserido.

Embora a hospitalização seja um período estressante, o retorno do familiar adoecido para o domicílio não diminui a sensação de angústia e de ansiedade, sentimentos vividos durante a internação. Para o cliente e a família a alta hospitalar pode significar uma importante modificação no padrão e nos hábitos de vida, que serão mais ou menos intensos conforme o papel representado pelo ente convalescido e pelo propenso cuidador.

\section{DISCUSSÃO}

Dentre muitos aspectos, o fenômeno apresentado possibilita compreender que diversos fatores, que vão desde as características e hábitos de vida do familiar antes do acidente vascular cerebral, passando pelas sequelas, limitações e necessidades decorrentes do evento, são vivenciados pelo cuidador familiar interferindo no significado que estes concedem à alta hospitalar.

No que se refere à possibilidade da alta hospitalar, bem como no tocante ao cuidado no domicílio, percebem-se sentimentos flutuando entre a felicidade, por ver o familiar se recuperando, e a extrema amargura, referente à novidade de tornar-se o cuidador familiar. Portanto, o contexto vivido pelo ente adoecido e pelo cuidador familiar revela um duelo de 
sentimentos, de manifestações, de atitudes e de práticas.

De tal modo, trata-se de campo fértil para a atuação do enfermeiro. Uma família bem orientada a respeito do processo saúde-doença torna-se mais equilibrada para auxiliar na recuperação, bem como enfrentar as limitações impostas pelo AVC. A família precisa receber suporte da equipe de enfermagem para aprender a cuidar no domicílio e, também, lidar com seus conflitos e seus medos.

São muitos os desafios vividos no domicílio após a alta hospitalar. Cliente e família necessitam desenvolver diferentes atividades. As autoras dizem que essa necessidade de resolutividade requer certo grau de preparo, visando reduzir os conflitos inerentes a este novo evento - cuidar de um ente enfermo. É neste contexto que o enfermeiro deve se preocupar em oferecer as orientações básicas de como cuidar no domicílio ${ }^{8}$.

No cuidado de enfermagem há, no mínimo, dois sujeitos implicados nesta ação, enfermeiro e cliente, que interagem, dialogam, constroem e reconstroem conhecimentos, além de atribuir sentido às ações e reagirem às experiências que compartilham ${ }^{9}$.

A família, inclusive, poderá colocar-se em situação de não apta para cuidar. Neste caso, o sistema de saúde deve prever recursos estratégicos que possam amparar tal situação. Não é possível ignorar isso. Logo, pode existir, de fato, a impossibilidade para cuidar do ente no domicílio, situação que precisa ser tratada com a responsabilidade que sublinha a notória e emblemática frase expressa na Constituição Brasileira: "Saúde é um direito de todos e é um dever do Estado".

Portanto, em "Percebendo que a teia social modula e modifica a significação da alta hospitalar", temos um conjunto de eventos que orientam o desenvolvimento do fenômeno e, que, portanto, se configura como o contexto. Todos os aspectos contextuais são, para os propensos cuidadores familiares, símbolos significantes que auxiliam na organização do comportamento e na tomada de ação.

As ações do cuidador familiar são mediadas por significados. As autoras apontam que, após enfrentar o mundo que o cerca, o indivíduo é chamado a agir, ou seja, a enfrentar as situações com as quais se depara. Para chegar a tal, ele reflete, interpreta e determina sua ação à luz das suas reflexões ${ }^{10}$.
A falta de informações adequadas por parte dos profissionais de saúde tem sido associada às dificuldades encontradas após o AVC. Contudo, ainda que na prática o planejamento da alta seja reconhecido pela Organização Mundial de Saúde e pelo Sistema Único de Saúde como uma estratégia para a integralidade do cuidado, a realidade mostra que este processo precisa de avaliações mais aprofundadas, deixando de ser meta para transformar-se em algo real.

Compreender o processo de cuidar no domicílio permite identificar carências e fragilidades para as quais o enfermeiro pode dirigir sua atenção, elegendo prioridades e concentrando seu trabalho ${ }^{11}$. Assim, é relevante focalizar o contexto familiar, pois, sem considerar as inúmeras possibilidades de estrutura familiar, e ignorando as diferentes perspectivas dos membros de uma unidade familiar, não será possível analisar a realidade e planejar o cuidado domiciliar. Portanto, existe a necessidade de conceber a família como um sujeito coletivo, traçando estratégias que considerem a estrutura e as relações destes indivíduos.

Não poderia deixar de ser expresso que cada família possui uma inserção histórica, cultural e social e, nesta acepção, sublinhando o universo simbólico, cada família terá um desenho próprio de ações e atitudes, que deverá ser captada pelos profissionais de saúde (ou deverá pelo menos ocorrer a tentativa), no sentido mesmo de uma compreensão holística e apropriada sobre quais são as possibilidades e potencialidades reais para cuidar com qualidade.

A abordagem interacionista defende que, ao confrontar o mundo de objetos que o rodeia, o ator social interpreta-o com o intuito de agir. 0 fenômeno em questão trata do mundo de vida desses familiares, que vivenciam a necessidade de assumir 0 cuidado, precisando, para tal, decifrar uma série de novos símbolos que envolvem a situação em tela, podendo então conferir significado a alta hospitalar do ente com sequelas do AVC.

Quando a enfermidade é grave, a família age, reage e interage internamente e com o contexto social em que vive para ajudar e apoiar o membro doente ${ }^{12}$. Este comportamento é uma forma de cuidado que a família desenvolve para garantir proteção ao familiar adoecido.

Quadro 1-Perfil dos familiares que participaram do estudo. 2012, Rio de Janeiro, Brasil.

\begin{tabular}{|l|l|l|l|l|l|l|l|l|}
\hline Pseudônimo & Sexo & Idade & Parentesco & Atividade atual & $\begin{array}{l}\text { Estado } \\
\text { civil }\end{array}$ & $\begin{array}{l}\text { Idade e sexo do } \\
\text { familiar } \\
\text { hospitalizado }\end{array}$ & $\begin{array}{l}\text { Tempo de } \\
\text { hospitalização }\end{array}$ & $\begin{array}{l}\text { Responsabilidade } \\
\text { pelo cuidado após } \\
\text { alta }\end{array}$ \\
\hline E1 & F & 42 & irmã & $\begin{array}{l}\text { atendente de } \\
\text { restaurante }\end{array}$ & solteiro & $48 / \mathrm{F}$ & 2 meses & total \\
\hline E2 & F & 31 & filha & $\begin{array}{l}\text { dona de casa } \\
\text { solteira }\end{array}$ & $64 / \mathrm{M}$ & 5 meses & parcial \\
\hline E3 & M & 58 & cônjuge & $\begin{array}{l}\text { gerente } \\
\text { administrativo }\end{array}$ & casado & $59 / \mathrm{F}$ & 2 meses & parcial \\
\hline E4 & F & 55 & cônjuge & $\begin{array}{l}\text { promotora de } \\
\text { eventos }\end{array}$ & casada & $78 / \mathrm{M}$ & 2 meses & total \\
\hline E5 & F & 61 & filha & $\begin{array}{l}\text { dona de casa } \\
\text { Eolteira }\end{array}$ & $85 / \mathrm{M}$ & $\begin{array}{l}1 \text { mês e } 15 \\
\text { dias }\end{array}$ & total \\
\hline E6 & M & 29 & filho & $\begin{array}{l}\text { analista de } \\
\text { sistemas }\end{array}$ & casado & $59 / \mathrm{F}$ & 2 meses & parcial \\
\hline E7 & F & 39 & filha & $\begin{array}{l}\text { professora } \\
\text { divorciada }\end{array}$ & $69 / \mathrm{M}$ & 1 mês & parcial \\
\hline E8 & F & 55 & filha & $\begin{array}{l}\text { auxiliar de } \\
\text { escritório }\end{array}$ & casada & $74 / \mathrm{F}$ & 4 meses & parcial \\
\hline E9 & M & 51 & filho & $\begin{array}{l}\text { professor } \\
\text { casado }\end{array}$ & $76 / \mathrm{M}$ & 2 meses & parcial \\
\hline
\end{tabular}


Figura 1: Esquema diagramático do fenômeno: "percebendo que a teia social modula e modifica a significação da alta hospitalar". 2012, Rio de Janeiro - Brasil.

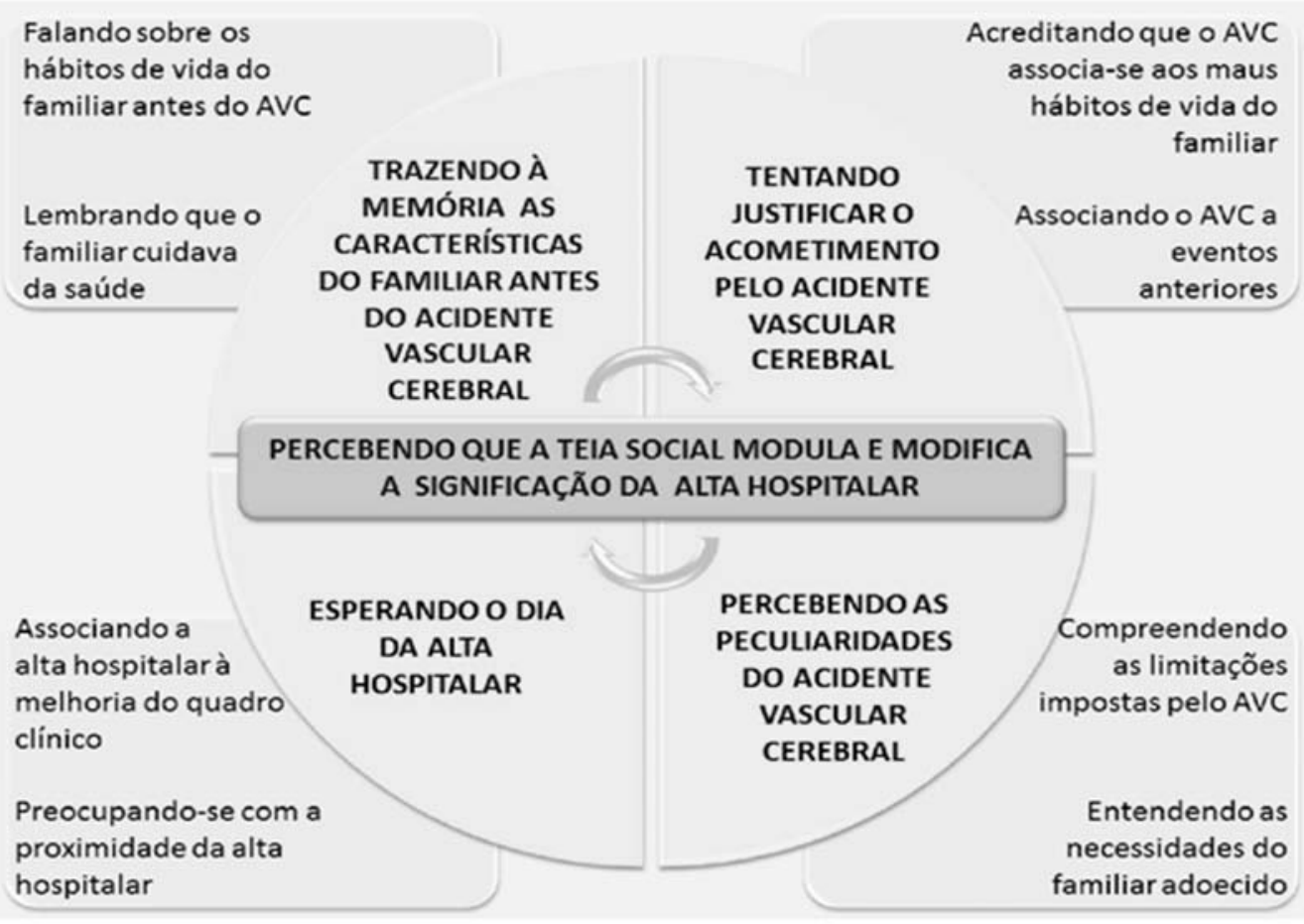

\section{CONCLUSÃO}

Diante de uma doença crônica, distintas modificações ocorrem na vida do indivíduo, levando-a a enfrentar perdas, limitações e frustrações. As transformações requeridas tendem a ser definidas considerando o tipo de doença, seu curso, bem como 0 significado que o sujeito adoecido e os familiares atribuem ao evento. Os papéis e as funções são repensados e redefinidos, de forma a auxiliar a pessoa convalescente a enfrentar o processo de adoecer. Logo, adoecer é parte de um movimento, não é uma situação estanque.

A presença de um familiar de paciente com sequelas limitantes (que demandam cuidados) conduz a muitas e significativas mudanças estruturais na teia social, atingindo fortemente os membros da família. Estes reagem e adotam estratégias de enfrentamento, que podem incluir o acolhimento e a proteção, buscando prover o cuidado, embora nem sempre desejem e estejam preparados para desenvolver tais atitudes/ações.

A equipe de saúde precisa compreender a importância das ações para além dos muros hospitalares. Logo, faz-se necessário discutir e propor o cuidado de forma mais includente, ou seja, familiares devem ser verdadeiramente ouvidos no tocante as suas percepções. 0 compartilhamento de ideias e, fundamentalmente, 0 diálogo precisam ter espaço nas práticas de saúde. Também, é preciso adequar a linguagem para que assuntos cabíveis ao cuidado possam fazer nexo ao ente e a família.
Preparar para alta hospitalar, desde o momento da admissão, possibilita o estabelecimento de diálogo e compartilhamento de saberes em caráter contínuo, que contribui intensamente para o desenvolvimento de autonomia e confiança necessárias para a prática do cuidado no domicílio, em vez de prescrições prontas, que precariamente orientam os clientes e os familiares.

0 ideal é que os cuidadores familiares participem e acompanhem as decisões e os rumos que são essenciais para a assistência ao familiar adoecido no domicilio, sabendo que poderão contar com o apoio das equipes de saúde. Quando recebem apoio técnico e emocional, podem exercer o cuidado e permanecer inseridos na sociedade, minimizando a sobrecarga advinda da difícil tarefa de atender às necessidades de uma pessoa dependente, ou mesmo parcialmente dependente, quando do seu retorno à residência.

\section{REFERÊNCIAS}

1. Ministério da saúde (Brasil). Secretaria de vigilância em saúde. Uma análise da mortalidade no Brasil e Regiões. [citado em 2010 mar. 20]; 2004 Disponivel em: http://portal.saude.gov.br/portal/saude/Gestor/ visualizar_texto.cfm?idtxt $=24421$.

2. Schaurich D. Compreensões de acadêmicos de enfermagem sobre famílias: algumas reflexões. Rev. Esc. Enf. Esc. Anna Nery. 2009 abr./ jun.; 13(2): 415-20. 
3. Luzardo AR, Waldman, BF. Atenção ao familiar cuidador do idoso com doença de Alzheimer. Acta Sci. Health Sci. 2004. 26(1), p. 135-45.

4. Chagas, DR. Cuidado participativo a paciente psiquiátrico: uma construção pautada na teoria de Imogene King[Dissertação]. Florianópolis(SC): Universidade Federal de Santa Catarina; 2000.

5. Blumer, H. Symbolic interacionism perspective and method. Califórnia: Prentice-Hall; 1969.

6. Santos S. dos, Nóbrega M.M.L. da. A grounded theory como alternativa metodológica para a pesquisa em enfermagem. REBEN. 2002 set./out.; 55(5), p. 575-9.

7. Strauss A, Corbin, J. Pesquisa qualitativa: técnicas e procedimentos para o desenvolvimento de teoria fundamentada. 2. ed. Porto Alegre(RS): Artmed; 2008.

8. Lavinsky AE; Vieira, T. Processo de cuidar de idosos com acidente vascular encefálico: sentimentos dos familiares envolvidos. Acta Sci. Health Sci. 2004.

26(1): 41-5;

9. Ferreira MA. A prática da ciência e da arte de cuidar e as exigências à produção e difusão do conhecimento. Esc. Anna Nery Rev. Enferm. 2008 jun./ago.; 12(2): 205-7.

10. Machado ALG; Jorge MS; Freitas CHA. A vivência do cuidador familiar de vítima de Acidente Vascular Encefálico: uma abordagem interacionista. REBEN. 2009 mar./abr.; 62(2): 246-51.

11. Perlini, NMO.; Faro, ACM. Cuidar da pessoa incapacitada por acidente vascular cerebral no domicílio: o fazer do cuidador familiar. Rev. Esc. Enferm. USP. 2005 jun.; 39(2): 154-63.

12. Marques SM, Ferraz AF. A vivência do cuidado domiciliar durante o processo de morrer: A perspectiva de familiares cuidadores. REME rev. min. enferm. 2004; 8(1): 165-252, 